\title{
Television and Media Literacy in Young Children: Issues and Effects
}

\author{
in Early Childhood
}

\author{
Kamaruzaman Jusoff (Corresponding author) \\ TropAIR, Faculty of Forestry, Universiti Putra Malaysia, 43400 Serdang, Selangor. Malaysia \\ Tel: 60-3-89467176 E-mail: kjusoff@yahoo.com \\ Nurul Nadiah Sahimi \\ School of Education, University of Massachusetts Amherst \\ Amherst, MA 01003-9297, USA \\ Tel: 413-883-8945Ｅ-mail: nadiahns@yahoo.com \\ This project is financed by University of Massachusetts (Sponsoring information)
}

\begin{abstract}
Television viewing among young children has been an on going issue as it is found to effect their development in various areas. This problem is getting more worrisome as the percentage and amount of hours of television exposure among young children is increasing, especially with the growing production of children television programs. Studies have found that television exposure to young children could effects their language and cognitive development, lead to behavior problems, attention disorder, aggression and obesity. This paper will discuss the issues of television exposure to young children, and the effects of promoting media literacy.
\end{abstract}

Keywords: Television viewing, Children television programs, Behavior problems

\section{Introduction}

Television is an important tool for most people, young or old, as today most information are delivered to the public via this technology. It can now be assessed easily via cables or satellite, which could provide consumers with every type of information that they need, either for work, leisure, interest, and so forth. With the emergent of this media and the production of various programs, television has caught the attention of most people. Comparable to other media, television is the most accessible media to most people, including young children, where television is their most favorite form of media (Burton). The use of television by young children particularly has raise debates and concerns to many organization and researchers (e.g. Anderson \& Pempek, 2005; Griffiths \& Machin, 2003) due to the boundless access to various types of information which could affect their development, behavior, health and learning.

For the past 15 years, the American Academy of Pediatrics (AAP) has put their concerns about the amount of time children spend viewing the television (AAP, 2001). Referring to the AAP guidelines, children older then 2 years old should watch no longer than 1 to 2 hours of quality programming, and children under 2 years old should not have any television viewing, as the first 2 years of life is a critical period for brain development. In addition, no media should be in the child's room, especially young children. However today, it is an epidemic scenario for children to ask for their personal television in their own bedroom. In a study by Roberts, Folour, Rideout, \& Brodie (1999), it is reported that $32 \%$ of the children between 2 to 7 years old and $65 \%$ of 8 to 18 years olds have television sets in their bedrooms (AAP, 2001). These percentage leads to an estimation of 3 hours per day of television and an average of 6 hours 32 minutes per day with various media combined (AAP, 2001; Roberts et al., 1999).

Looking at this scenario, it is still not clear to many researchers why parent could allow media to be in these young children room, with access to various channels and leaving them to watch television by their own. One possibility might be that parents believe that media could offer a positive learning environment, and that children could develop certain skills from viewing TV. This is shown in a study by Dalzell \& Msall (2000) where majority of parents of 0-35 months old believed that television could improve a child's vocabulary (Certain, \& Kahn, 2002).

With the production of more young children television programs, such as Baby Einstein and Teletubbies, it has substantially increased the amount of foreground television for young children (Anderson \& Pempek, 2005). In a survey by Pierroutsakos, Hanna, Self, Lewis, \& Brewer (2004) on 100 parents on the amount of time that children aged 2 and younger attend to the television, it is reported that their infants were exposed to about 120 minutes of TV per day, $50 \%$ of which was infant and toddler programming, $40 \%$ adult programming, and $9 \%$ preteen programming (Anderson \& Pempek, 2005). Regardless the amount of time that these young children used to watch TV at home, it is currently reported that 70 percent of the child care centers today use television during a typical day, and in one year, an average 
child would spend about 900 hours in his school and nearly 1,023 hours in front of a television (Gavin, 2005). It is then estimated that at average the television is on for approximately 7 hours a day and when the child graduated from high school, he or she might have watched 15,000 hours of television (Sparrow, 2007). These figures shows that there are increments in the numbers of hours spent in a child's life, which illustrates the changes of life-style in the youngsters today which television place a huge influence in their daily activities. However, these percentages are reported higher in low to moderate income families, because such families are found to use television extensively (Huston \& Wright, 1997; Wright, Huston, Murphy, Peters, Pinon, Scantling, \& Kotler, 2001). In a survey by Certain \& Kahn (2002) the percentage of hours on young children watching television is related to several variables, which include early television viewing and maternal education. Their longitudinal study indicates that greater television viewing in early childhood is associated with greater viewing at school age, due to continuing environment influence, child preferences or habit, or the interaction of both, and less educated mothers tend to watch more television at all ages. Regardless of the variables above, child care, maternal employment and marital status were found not among the strongest predictor of increased television viewing (Certain \& Kahn, 2002). Hence, this runs to the notion that these scenarios probably due to more productions of children's television programs, such as Sesame Street (Wright et al., 2001) as well as parenting style, where excessive television viewing is allowed to the child as an easy way out for parents to calm them down as parents runs their errands (Certain \& Kahn, 2002; Gadberry, 1974). Such parenting style has first been reported in earlier studies where parents has used television to baby sit their child, as television was associated with significantly more attention shifts, sitting and self-stimulation (Gadberry,1974). Therefore, it is then to be questioned why such parenting styles still exist when many concerns about TV and young children are being addressed and more parents are being more 'media educated'. A few rationale reasons that could reflect this scenario might be to having more working parents, or parents are loaded with various daily agendas due to financial constrains, personal problems, family errands, or it is the family members habit to watch television in their free time. Any of these scenarios could put their child to television addiction, which will eventually affected their child's daily activities, that leads to an unhealthy childhood experience and later development (e.g. Anderson, Huston, Schmitt, Linebarger \& Wright, 2001; Hapkiewiez, 1979; Healy, 2004) and many health issues (e.g. Klesges, Shelton \& Klesges, 1993; Pine \& Nash, 2002).

According to the American Academy of Pediatric (2001), as much as $10 \%$ to $20 \%$ of real life violence may be attributable to media violence. The recently completed 3-year National Television Violence Study found that nearly two thirds of all programming contains violence, with children's programs contain the most violence, portrayals of violence are usually glamorized and perpetrators often goes unpunished (AAP 2001; Federman,1998). Besides that, a recent comprehensive analysis of music videos found that nearly one fourth of all Music Television (MTV) videos portray overt violence and depict weapon carrying (AAP, 2001; Durant, Rich, Pmans, Rome \& Alfred, 1997). Additional to that, along with the main course of programs, commercials are showed, promoting various types of children items. It is reported that the commercials in prime time programming has steadily increased so that today at least 16 minutes of an hour-long show are devoted to the advertisements, with the average of more than 40,000 television commercials per year (Christakis, 2006). Many previous and recent researches have reported more negative outcomes rather than positive outcomes, which is a worrying scenario for parents and professionals. Therefore, it is important for parents to teach their children to be media literate, as young children are particularly vulnerable to the message conveyed through television, which could influence their perception and behaviors (AAP, 2001).

\section{Issues in television viewing and young children}

Television viewing among young children has raised issues and concerns to many researchers and professionals. As television series can be affectionate to watch, it could glue children on the couch; continuously watching one program after another. Many studies have found that children who live in 'heavy' TV-viewing households are more likely to have poor academic performance (e.g. Razel, 2001), violence (e.g. Ni Chang, 2000) and health problems (e.g. Christakis, 2006). However, to put such blame on each viewers does not seems appropriate as the effects on television viewed by young children might differ as they passed through a certain stage of age.

\subsection{Attention disorder}

Early television exposure is now a common scenario, where babies as young as a few months old are exposed to either foreground and background television. In a recent study by Christakis (2006), it is reported that there is an association between early television viewing and later symptoms of attention disorder (Anderson \& Pempek, 2005; Healy, 2004; Obel, Henriksen, Dalsgaard, Linnet, Skajaa, Thomsen, \& Olsen, 2004). Time spent TV viewing (without reference to content) was assessed from parent estimates when the children were $11 / 2$ to $31 / 2$ years old, and symptoms of attention disorders were assessed at age 7 years old based on maternal report of child behavior including restlessness, concentration problems, impulsiveness, confusion and obsession. The finding shows a small positive association between viewing at both ages of $11 / 2$ years old and $31 / 2$ years old and having symptoms of attention disorders. Besides, it is also reported that there is a $9 \%$ increase in risk of attention problem for each daily hour of television-watching. Healy (2004) reported that these cases could happen due to the power of environmental 
experiences in shaping the developing brain because of the plasticity of its neuronal connectivity. Repeated exposure to any stimulus in a child's environment may forcibly impact mental and emotional growth by either setting up particular circuitry ("habits of mind") or depriving the brain of other experiences (Healy, 2004).

However, in a duplicate study by Obel et al. (2004) in Denmark, they found no significant association between hours of watching television and behavioral problems in any of the age groups, even though for those who spend the longest time in front of the television. However, they reported that the children in their study who were watching television for more than $1 \frac{1}{2}$ hours at the age of $3 \frac{1}{2}$ were more likely to have ADHD-like behavior already at that age, as compared to Christakis (2004). Analyzing both findings, these contrasts probably due to US children apparently watch much more television than Danish children (Obel et al., 2004). Besides, as these studies focuses only on the amount of time children viewing the television, there might also be a possibility that the content of the program could also put effect to the result of the study, as many other studies have suggested that content is a crucial part of television viewing which could affect several areas of development.

\subsection{Learning}

Previous and recent studies have been done to see the effect between television viewing and school achievement, including language and cognitive skills. Correlational studies show a small but consistent negative relation between concurrent total viewing and various indices of school achievement (Comstock, 1995; Wright et al., 2001). In the other hand, positive outcomes are also found in correlation to language development (Anderson et al., 2001), cognitive development (Diaz-Guerrero \& Holtzman, 1974; Carew, 1980) and positive school achievement (Razel, 2001; Uchikoshi, 2005). However, several studies have found that television could promote positive development and learning outcomes for younger children and negative results on older children, and vice versa.

In two studies using Sesame Street program, (Linebarger \& Walker, 2005; Nelson, 1973) negative associations of language development are reported on children younger than the age of 2 years old (Anderson \& Pempek, 2005). However, in contrast Rice, Huston, Truglio, \& Wright (1990) found that there is positive language development among children at 24 months old and older with watching Sesame Street. This is because Sesame Street have always considered their audience to be children 2 years and older, and there is a possibility that being too advance for younger children could actually hinders rather than promotes language development them (Anderson \& Pempek, 2005). Besides, Uchikoshi (2005) in his study on Spanish-speaking English-language kindergartners watching Arthur, a children's television program, reported that routine and attentive viewing of Arthur can assist non-mainstream bilingual children to develop English narrative styles that match the English-speaking school norms faster, even prior to formal literacy instruction. Hence, this shows that to successfully promote language development in young children, language learning via television should only be introduced to children older then 24 months old, as most programs are produced for children at this age and older, and also probably due to the readiness of these very young children to perceive such level of information.

The same patterns of results are also reported in studies on young children television viewing and cognitive development. In two studies reviewed by Anderson \& Pempek (2005), Wachs (1986) found that background noise from the television is associated with poorer cognitive development on infants and toddlers. Carew (1980) in his longitudinal study on the impact of six "intellectual sources" on spatial and language skills related to intelligence, his results were consistent with the hypothesis that television had a negative impact on cognitive development during the first 2 years of life but the impact became positive for children 24 months old and older. This is probably because very young children are sensitive to the sequential and linguistic comprehensibility of video to at least 18 months of age (Anderson \& Pempek, 2005), and also that very young children have difficulty using a symbolic representation as a source of information about an existing situation (Troseth, \& DeLoache, 1998) which explains that they are most likely not developmentally ready to receive information or learn from the television.

Inconsistent findings have been reported, in previous and recent studies on television viewing and school achievement. Negative relationship is found between television viewing and school achievement - the more a student views television, the lower are his or her educational achievements (Razel, 2001; Williams, Haertel, Haertel, \& Walberg, 1982), positive relationship - the more the student views television, the higher his or her educational achievement (Blosser, 1988; Razel, 2001) and no relationship between television viewing and educational achievement (Razel, 2001; Scarborough, 1989). However, in recent studies by Razel (2001), different results are obtained for children of different ages towards television viewing and school achievement. Positive correlation are found for children ages 5 and 6 , average negative correlation among children ages 7 to 9 and even more negative correlations are found among older children and adolescence; 10 to 17 years old. Hence, it is to be questioned, if children older than 24 months old tend to show positive language and cognitive development due to the appropriate content viewed by these young children, why as these children gets older, their school achievement tend to decrease? Razel (2001) concluded that it is possible that the amount of television viewing is responsible for lowered achievement, similar as suggested earlier by the National Assessment of Educational Progress, (1994) that poor achievers tend to watch more television, where else Numan (1986, 
1988 , 1995) stated that socioeconomic status (SES) is responsible for the low achievement and Hornik (1981) cited IQ as the cause (Razel, 2001).

Regardless to the above reasons, as television is accessible to most young children and adolescence, with hundreds of channels that they receive from cables or satellite, the entertainment from this media could be endless to them, which could affect their time management, and influence their tendency to keep on watching the television. In an interview by Ballard (2003) on children between age 8 and $13,75 \%$ of the children reported that watching television sometimes or often kept them from getting their homework done, which makes them keep on wanting to watch and makes school work boring. Looking at these scenario, there is also a possibility that older children tend to watch more television as they probably have more access to the television compared to younger children, which also could eventually affected their school performance due to more homework and higher level of instruction where they usually need to put more attention and focus on their studies.

\subsection{Aggression}

One of the most worrying behaviors that parents faced with their young children today is the tendency to perform any motion of aggression. Many television shows today tend to insert aggression behavior in most of the scenes, which is not just the actions of kicking or hitting, but to the extent of raping and killing. In 1990, the National Association for the Education of Young Children has raised their concern in the NAEYC position statement where they stated that there has been an increase in the number of reported violent acts directed at children and severity of violent acts observed by children through the media, including television (p.18) (Ni Chang, 2000). In relation to that according to the American Psychological Association Task Force on Television and American Society, by their graduation from elementary schools, children will have seen 8,000 killings and more than 10,000 other acts of violence (Carter, 1995; Ni Chang, 2000).

Many believed that there is a correlation between an excessive viewing of violence on television and children's exhibited aggressive behaviors (Hapkiewiez, 1979; Ni Chang, 2000; Rothenberg, 1985). In an experiment on aggressive behavior among preschool children, the results show that children who viewed aggressive programs showed significantly greater increases in aggressive behavior than those who watched non aggressive programs. Analyzing the above scenario, it reflects Bandura social learning theory, where most human behavior is learned observationally through modeling, which involve observing others forms an idea of how new behaviors are performed, and on later occasions it will serves as a guide for action (Berks, 1994). Hence when young children continuously watch aggressive actions from the television, there will always be a tendency for them imitate the actions, thinking such actions as part of their play, which could lead to actual aggressive behavior. This is because repetition of violence in the mass media could results in a decreased emotional sensitivity to media violence and increased probability for decreased emotional sensitivity to actual aggressive behavior in real life situations (Rothenberg, 1985).

\subsection{Advertisement}

With the increment of television viewers' percentage in the recent years, the number of advertisement has also increased, which presents products for people of all ages. Recently, Christakis (2006) has reported that the commercials in prime time programming have steadily increased so that today at least 16 minutes of an hour-long show are devoted to the advertisements, which focuses for the targeted viewers based on the type of program being showed at the time. For example, when children television programs are being broadcasted, there will be advertisement that is intended for children, which is mostly about food and toys. Previous and recent studies have raised their concern on the effect of advertisement towards children behavior (e.g. Feshbach, Dillman, \& Jordan, 1979; Greer, Potts, Wright, \& Huston, 1982) and whether young children are capable to understand the information being advertised (Chan \& McNeal, 2004; Levin, Petros, \& Petrellsa, 1982).

Obesity and consumption of unhealthy food among children has raised concern among pediatricians. Christakis (2006) reported that in 1997 food manufacturers spent $\$ 7$ billion in advertising processed and packaged foods, where more than $90 \%$ of these advertisements which are shown in between children programs, are focused on high-sugar cereals and candy bars, salty canned foods, fast food or other junk food. In result, there has been a $54 \%$ increased in obesity among children between 6 to 11 years old, and a 98\% increase in extreme obesity over a year period (Klesges et al., 2001). The increment in obesity is reported due to increases in the consumption of foods commonly advertised on television, where each hour increase in television viewing was associated with an additional $167 \mathrm{kcal} / \mathrm{s}$ (Wiecha, Peterson, Ludwig, Kim, Sobol, \& Gortmaker, 2006), and less exercise (Klesges et al., 2001). This is supported by a study by Vandewater, Shim, \& Caplovitz (2004), where it is reported that children who use a lot of media have a lower activity level, which results on lower metabolic rates during television viewing compared to resting periods among normal weight children (Klesges et al., 1993)? This is probably because during television viewing, there will be less physical activities, which could extend for several hours. 
Another concern on the effects of advertising on young children is the influence of advertisement towards their behavior. Many consider children to be more vulnerable than adults to the impact of images on television (Huston, Zillman, \& Bryant, 1994; Larson, 2003), as they are lack of cognitive skills to protect themselves against advertising messages (Buijzen \& Valkenburg, 2003). Young children generally think that television advertising is informative, truthful and entertaining (Chan \& McNeal, 2004), and they are usually influenced by the advertisement as soon as they begin watching the television (Levin et al., 1982). Buijzen \& Valkenburg (2003) reported that advertising could enhance materialism, parent-child conflict and unhappiness. As most advertisement ideology focuses on the notion that possessions are important and those desirable qualities, such as beauty, success and happiness can be obtained only by material possessions (Buijzen \& Valkenburg, 2003; Pollay, 1986; Wulfemeyer \& Muller, 1992), materialism was found to establish among children in early and middle childhood, as well as adolescents from families who do not discuss on consumption matters. Children tend to beg and crave for what they saw in the advertisement, which could either lead to parents being a genie granting their wishes, or in the other hand- a conflict. According to a study by Stoneman \& Brody (1981), children who had seen the candy and toy commercials tend to ask for the advertised products twice as often than those who had not been exposed, and these children have made approximately $50 \%$ more purchase requests than children who had not seen the commercial (Buijzen \& Valkenburg, 2003).

In a study by Greer, et al. (1982), it is found that children who saw high salience commercials were more aggressive after viewing than those who saw low salience commercials, which results in weaker tendency for imaginative play. They further explained that increased aggression following exposure to television characterized by high action, high pace, and high levels of visual change supports the hypotheses that such features lead to generalized arousal which in turn increases the likelihood of aggressive behavior in a situation where there are cues for that kinds of behavior (Greer et al., 1982).

\section{Importance of media literacy}

The definition of media literacy has been defined in many studies, but it all focuses on "the ability to access, understand and create communications in a variety of contexts (Ofcom, 2004). In other words, it is the ability to read and understand the visual, aural and digital messages and having the skills to understand and interact with the media analytically, critically and knowledgably (Burton, 2005). With the emergent of various television programs and the issues that are being raised by researchers on young viewers, media literacy is thus, an important aspect that everyone need to learn, as the language of the media is as complex and interesting as our verbal and written language and therefore, it is important for us to be articulate in it (Burton, 2005).

In reality, many researches would argue that children today are more media literate than the children of previous generations, and indeed significantly more media literate than their own parents (Ofcom, 2004). However, to what extend can a child be acknowledged as media literate? Can a 4 year old child be seen as media literate when he knows how to turn on the television and browse the channels himself? Although he probably knows how to get access to the channels or programs that he wants, being media literate is also depends on his ability to perceive and understand the information on the television. However, it is reported that young children cannot discriminate between real and imagination (AAP, 2001) and they do not have the ability to regulate their desire and behavior to what they see on television.

The use of television among young children has raised many issues, as discussed above which has put great concern to parents, professionals and researchers. Looking back at the content of television programming that we could access from cables and satellite, the amount of advertisement, violence, and other unhealthy behavior and scenes are being broadcasted for the viewing of the audience. Regardless of the issues raised above, whether TV is harmful or not, depends on several factors; what is being watched, who is watching, with whom, while doing what and for how long (Sparrow, 2007). Hence, it is then the role of parents particularly (as television are watched most at home), to teach their young children about media literacy. This is because, when children are thought to be media literate, they could become a more savvy TV viewer, who are able to distinguish reliable information from manipulation (Sparrow, 2007) and thus gradually reducing the problems addressed above.

Sparrow (2007) has suggested several ways on how parents could teach their young children to be media literate. Despite setting limits, reducing and carefully choosing channels for young children and school age children viewing, it is suggested that parents discussed with their young children about what is right and what is wrong, especially on aggressive behaviors. This is because when adults express disapproval of on-screen behavior, raise questions about the realism of televised information, and encourage children to discuss I, they teach children to evaluate television content rather than accept it uncritically (Berks, 1994). Besides, when parents engaged children with moral reasoning, they tend to engage children in social problem solving and prosocial acts, such as helping, sharing and defending victims of injustice (Berks, 1994). More over, as young children are easily influenced by television commercials that are targeted to them, Sparrow (2007) suggested that parents watch the television commercials together with their children and create a discussion about the program being watched. It is important for parents to encourage their young children to wonder 
about advertisements, the advertiser's motives, and the effects of consuming the advertised products, so that they understand the real meaning of advertisement, as well as preparing them to be a better consumer.

\section{Conclusion}

The use of television among young children as well as school age children has been critically discussed by many previous and recent researches. This is because there are more negative outcomes that can be seen among these children due to excessive amount of television viewing and also with the broad range of content being broadcasted, which include violent, sexual, alcohol and so forth. Thus, it is now important for parents to make sure that their children are media literate so that they could later be a better consumer, being prosocial, and develop other positive development. However, as young children today are the people of tomorrow, it is important for them to be media literate once they are exposed to the television, as it would be easier for parents to develop their children with positive behavior and attitude at a younger age.

\section{References}

American Academy of Pediatrics. (2001). Children, Adolescents, and Television. Pediatrics, 107(2), 423-426.

Anderson, D.R., Pugzles, E. L., Field. \& Sanders, J. (1981). The Effects of TV Program Comprehensibility on Preschool Children's Visual Attention to Television. Child Development. 52, 151-157.

Anderson, D.R, Huston, A.C., Schmitt, K.L., Linebarger, D.L., \& Wright, J.C. (2001). Early childhood television and adolescent behavior: The Recontact study. Monographs of the Society for Research in Child Development, 66 (1, Serial No. 264)

Anderson, D.R. \& Levin, S.R. (1976). Young Children's Attention to "Sesame Street". Child Development, 47, 806-811.

Anderson, D.R. \& Pempek, T.A. (2005). Television and Very Young Children. The American Behavioral Scientist, 48(5), 505-522.

Ballard, K.D. (2003). Media Habits and Academic Performance: Elementary and Middle School Students' Perceptions.

Berks, L.E. (1994). Child Development ( $3^{\text {rd }}$ ed.). Massachusetts. Allyn and Bacon.

Buijzen, M. \& Valkenburg, P.M. (2003). The effects of television advertising on materialism, parent-child conflict, and unhappiness: A review of research. Applied Developmental Psychology, 24, 437-456.

Burton, L. What Is this Media Literacy Thing? The Australian Children's Television Foundation. Screen education, 38, 93-98.

Certain, L.K. \& Kahn, R.S. (2002). Prevalence, Correlates, and Trajectory of Television Viewing Among Infants and Toddlers. Pediatrics, 109(4), 634-642.

Chan, K. \& McNeal, J.U. (2004). Children's Understanding of Television Advertising: A Revisit in the Chinese Context. Journal of Genetic Psychology, 165(1), 28-36.

Christakis, D.A. (2006, April). The Hidden and Potent Effects of Television Advertising. Journal of American Medical Association, 295(14), 1698-1699.

Diaz-Guerrero, R. \& Holtzman, W.H. (1974). Learning by televised "Plaza Sesemo" in Mexico. Journal of Educational Psychology, 66, 632-643.

Feshbach, N.D., Dillman, A.S. \& Jordan, T.S., (1979, Spring). Children and Television Advertising: Some Research and Some Perspectives. Journal of Clinical Child Psychology, p. 26-30.

Gavin, M.L. (2005). How TV Affects Your Child. Nemours Foundation. Retrived April 12, 2007 from http://www.kidshealth.org/index.html

Gadberry, S. (1974). Television as Baby-Sitter: A Field Comparison of Preschoolers' Behavior during Playtime and during Television Viewing. Child Development, 45, 1132-1136.

Greer, D., Potts, R., Wright, J.C. \& Huston, A.C. (1982). The Effects of Television Commercial Form and Commercial Placement on Children's Social Behavior and Attention. Child Development, 53, 611-619.

Griffiths, M. \& Machin, D., (2003). Television and Playfround Games as Part of children's Symbolic Culture. Social Semantics, 13(2), 147-160.

Hapkiewiez, W.G. (1979, Spring). Children's Reactions to Cartoon Violence. Journal of Clinical Child Psychology, p. 30-34.

Healy, J.M. (2004). Early Television exposure and Subsequent attention Problems in Children. American Academy of Pediatrics, 917-918. 
Klesges, R. C., Shelton, M. L. \& Klesges, L.M. (1993, February). Effects of television on metabolic rate: Potential implications for childhood obesity. Pediatrics, 91, 281-286.

Larson, M.S. (2003). Gender, Race, and Aggression in Television Commercials That Feature Children. ProQuest Education Journals, Sex Roles, 48(1/2), 67-75.

Levin, S.R., Petros, T.V. \& Petrellsa, F.W. (1982). Preschools' Awareness of Television Advertising. Child Development, 53, 933-937.

Ni Chang. (2000). Reasoning with children About Violent Television Shows and Related Toys. Early Childhood Education Journal, 28(2), 85-89.

Obel, C., Henriksen, T.B., Dalsgaard, S., Linnet, K.M., Skajaa, E., Thomsen, P.H. \& Olsen, J. (2004). Does Children's Watching of Television Cause Attention Problems? Retesting the Hypothesis in a Danish Cohort. Journal of Pediatrics, 10,1542 .

Ofcom. (2004). The Media Literacy of Children and Young People. Youth and Media Institute of Education, London.

Pine, K.J. \& Nash, A. (2002). Dear Santa: The effects of television advertising on young children. International Journal of Behavioral Development, 26(6), 529-539.

Razel, M. (2001). The Complex Model of Television Viewing and Educational Achievement. Journal of Educational Research, 94, 6.

Rice, M.L., Huston, A.C., Truglio, R. \& Wright, J. (1990). Words from Sesame Street: Learning vocabulary while viewing. Developmental Psychology, 26, 421-428.

Rothenberg, M.B. (1985, Spring). Role of Television in Shaping the Attitudes of Children. CHC, 148-149.

Sparrow, J. (2007, April). Small Screen, Big Impact. Scholastic Parent \& Child, 48-50.

Thakkar, R.R., Garrison, M.M., \& Christakis,D.A. (2006). A Systematic Review for the effects of Television Viewing by Infants and Preschoolers. Pediatrics, 118(5), 2025-2031.

Troseth, G.L. \& DeLoache, J.S. (1998). The Medium Can Obscure the Message: Young Children's Understanding of Video. Child Development, 69(4), 950-965.

Uchikoshi, Y. (2005). Narrative development in Bilingual Kindergartners: Can Arthur Help? Developmental Psychology, 41(3), 464-478.

Vandewater, E.A., Shim, M. \& Caplovitz, A.G. (2004). Linking obesity and activity level with children's television and video game use. Journal of Adolescence, 27, 71-85.

Wiecha, J.L., Peterson, K.E., Ludwig, D.S., Kim, J., Sobol, A. \& Gortmaker, S.L. (2006). When Children Eat What They Watch: Impact of Television Viewing on Dietary Intake in Youth. Arch. Pediatric Adolescent Med. 160, $436-442$.

Wright, J.C., Huston, A.C., Murphy, K.C., Peters, M.S., Pinon, M., Scantlin, R. \& Kotler, J. (2001). The Relations of Early Television Viewing to School Readiness and Vocabulary of Children from Low-Income Families: The Early Window Project. Child Development, 72(5), 1347-1366. 